\section{Rosa Montero y el lenguaje de la esperanza}

\section{Tania Balderas-Chacón}

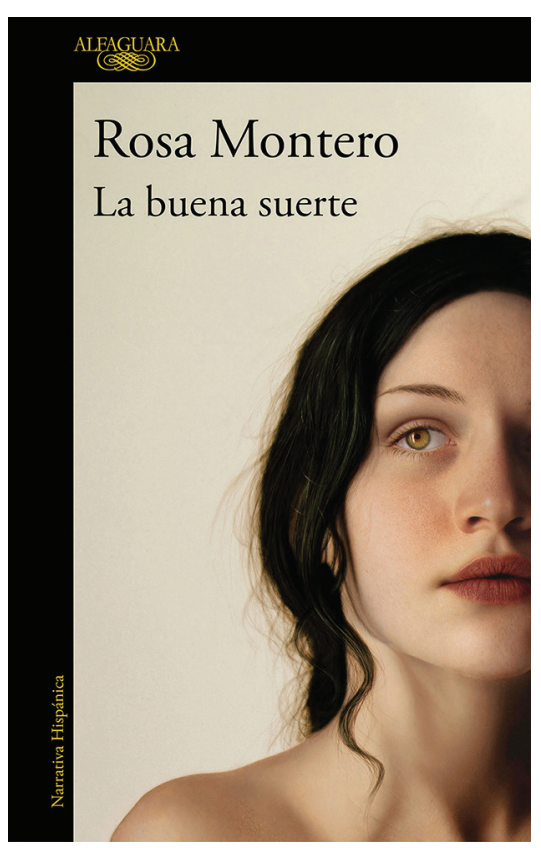

Rosa Montero, La buena suerte, ISBN: 9788420439457, Madrid, Alfaguara, $2020,328 \mathrm{pp}$.
U no de los tantos versos que la pluma de Ida Vitale ha plasmado en papel y que se encuentra dentro del poema "Deriva”, advierte: "Tener paciencia, pensar ser esperanza" (2018: 62). Desconozco el contexto original que produjo esa línea que, en cinco palabras, resume aquello a lo que algunos optimistas tratamos de aferrarnos tras un año con pocas noticias buenas y confinados dentro de un espacio que, tristemente para muchos, ha dejado de ser un hogar.

Ese mismo verso también podría colocarse como un tercer epígrafe para la novela más reciente de Rosa Montero, La buena suerte (2020), pues sus 328 páginas acogen una historia de esperanza donde la paciencia es indispensable.

Una jubilación en paz, un borrón y cuenta nueva, la amistad y el amor son algunos motivos que los personajes de esta historia han elegido como motor para que cada día cuente... Como muchos de nosotros. Sin embargo, esta no es tarea fácil, pues cada uno debe sobrellevar sus propios demonios: el abandono de una pareja, una paternidad interrumpida por el horror, unos pulmones exhaustos, algunos antecedentes psiquiátricos.

Todo el vaivén entre luz y oscuridad se desarrolla, además, en un escenario destartalado poco propicio para la alegría, la ficticia comunidad de Pozonegro, donde, más allá del supermercado, todo se vuelve "deprimente, pardo, indefinido, sucio, necesitado con urgencia de una mano de pintura y esperanza" (15). ${ }^{1}$

En ese gris rincón del mundo vive Raluca, una mujer que sobrelleva con entusiasmo la vida que todos los días se ofrece ante ella como un regalo tras haberse zafado de una relación disfuncional y violenta. Raluca trabaja en el supermercado, donde su bondad (iingenuidad?) es continuamente boicoteada por la única supuesta amiga que tiene ahí. Sin embargo, fuera de ese local, cuenta con el apoyo incondicional de su vecino Felipe y se refugia en la pintura. La sensibilidad de esta mujer no debe confundirse con debilidad, pues cuenta con la energía suficiente para defenderse e, incluso, interceder valientemente por los demás... aunque no siempre lo haga midiendo las consecuencias. Una licencia que, creo, sólo pueden tomarse aquellos que, como ella, se reconocen con suerte: "Yo es que siempre he tenido muy buena suerte, ¿sabes? Y

1 Todas las citas pertenecientes a La buena suerte corresponden a Montero, 2020, por lo cual sólo se anota el número de página. 
menos mal que soy así de afortunada, porque, si no, con la vida que he tenido, no sé qué hubiera sido de mí" (193).

Si Raluca es un ángel o un torbellino luminoso, Pablo es un abismo, una oración interrumpida por el miedo, emoción que aparece con frecuencia en la narrativa de Montero (incluso la estoica Bruna Husky llega a experimentarla), pero, en esta novela, su exploración del tema resonará con fuerza en los lectores que han incorporado el temor a su cotidianidad:

El miedo es un parásito, un invasor. Un vampiro que te chupa los pensamientos, porque no puedes alejarlo de tu cabeza. E incluso si, en un raro momento de tregua, consigues olvidar por un instante tu miedo, siempre queda cierta pesadumbre pendiendo sobre ti, una vaga premonición de riesgo y desgracia. No hay manera de librarse por completo de él (147).

Sin embargo, tenemos que vivir. Pablo volverá a hacerlo gracias a Raluca. Por último, quisiera dejar en claro que La buena suerte no es una obra ingenua, 'ligerita' ni 'bobalicona', es decir, no se trata de una novela con situaciones que frivolizan la complejidad de los seres humanos (consigo mismos ni con los demás); tampoco es un relato con salidas fáciles: los personajes que son felices saben que deben trabajar esa dicha, ganarle la partida al miedo. Esta obra de Rosa Montero, fiel a su estilo, incluye desde reflexiones dolorosas y personajes repulsivos hasta destellos de humor y escenas de belleza memorable. Todo para construir una historia de esperanza que le viene bien al 2021.

\author{
REFERENCIAS \\ Montero, Rosa (2020), La buena suerte, México, Alfaguara. \\ Vitale, Ida (2018), Procura de lo imposible, México, FCE.
}

TANia Balderas Chacón. Licenciada en Lenguas Modernas-Español por la Universidad Autónoma de Querétaro (UAQ), México, y Maestra en Literatura Mexicana por la Universidad Veracruzana (UV), México. Ha participado en distintos coloquios de investigación literaria y ha publicado reseñas y algunos cuentos en revistas como La palabra y el hombre y Cuadernos Fronterizos. Se ha desempeñado como docente a nivel secundaria, medio superior y superior. Ha colaborado en tres antologías de microficción publicadas por la Benemérita Universidad Autónoma de Puebla: Vamos al circo. Minificción hispanoamericana (2016); Cortocircuito. Fusiones en la minificción (2017); y Resonancias (2018). En 2019, publicó su primer poemario, El viaje de Laika (ParTres Editores). Actualmente, además de ser profesora, es coordinadora de la Preparatoria del Colegio Helen Parkhurst. 